\title{
Genes in Streams: Using DNA to Understand the Movement of Freshwater Fauna and Their Riverine Habitat
}

\author{
JANE M. HUGHES, DANIEL J. SCHMIDT, AND DEBRA S. FINN
}

\begin{abstract}
Today, decisions regarding the management and conservation of populations are often informed to some degree by population genetics. A fundamental measure sought by decisionmakers is the degree of connectivity between populations, which, when approached from a genetic perspective, may be influenced by many factors, making it difficult to generalize across taxa, habitats, or life histories. In the case of freshwaterlimited fauna, the shared constraint of habitat structure (e.g., a dendritic stream network) imposed on all species in the system simplifies the task. A number of models have been proposed that predict how populations of taxa with different life-history traits and dispersal capabilities interact within structured freshwater habitats of this kind. In this article, we summarize these models and illustrate the general patterns of phylogeographic structure expected to occur under different scenarios of freshwater population connectivity. Additionally, we describe how the genetic structure of stream inhabitants can reflect historical changes in the physical structure of streams and thus open a window on past patterns of connectivity. A greater understanding of these concepts will contribute to an improved multidisciplinary approach to managing freshwater ecosystems.
\end{abstract}

Keywords: molecular tools, stream ecology, riverine architecture, phylogeography

\section{$\mathbf{H}$} ow are populations of stream fauna connected in space? Direct approaches to addressing this central question in stream ecology have included mark-recapture studies (Lucas and Baras 2000); stable isotope labeling (MacNeale et al. 2005); and monitoring of new habitats, either by placing pieces of new habitat in streams (Mackay 1992) or by assessing changes after rehabilitation attempts such as the removal of dams (Stanley et al. 2002). Modern molecular tools provide an alternative approach, and a number of studies have been published reporting on the use of allozymes (e.g., Bohonak 1999) and, more recently, mitochondrial DNA (e.g., Finn et al. 2006, Hughes and Hillyer 2006).

The structure of the stream itself is likely to affect connectivity among populations of stream animals. Many authors have recognized the importance of the dendritic arrangement of streams, and the fact that they fit into a spatial hierarchy of reaches, streams, subcatchments, and catchments (Meffe and Vrijenhoek 1988, Lowe et al. 2006a, Grant et al. 2007). Thus, connectivity among populations is likely to be affected by the position of populations in the stream network; for example, whether populations occur in headwaters or tailwaters, or whether a species occupies a wide or narrow extent of the stream gradient. Distance itself is also likely to have an effect on connectivity, in that populations separated by longer stretches of stream channel are likely to be more isolated from one another than they are from nearby populations. Finally, the life-history and dispersal traits of the species of interest will certainly have some effect, and these traits most likely interact with population distribution in the stream network. In this article, we examine whether it is possible to combine these important factors to come up with a set of models to define patterns of connectivity among populations for a variety of types of stream-dwelling fauna.

A second question that stream biologists may ask is, How can current species distributions be explained? More specifically, what historical processes have contributed to the current distributional range of freshwater species? For example, many obligate freshwater species (such as fishes) occur in more than one drainage basin. Biogeographers propose that such patterns, wherein populations of a species occur in two or more isolated patches of habitat, most likely arise as a result of (a) vicariance (the habitat was historically continuous but 
subsequently became fragmented) or (b) dispersal (individuals somehow managed to disperse from one habitat patch to another). Molecular data can be used to discriminate between these alternatives, and the application of this approach to explain current distributions of freshwater organisms will be discussed in this article.

A third question is, How can molecular data reveal patterns of historical change in the physical landscape? Riverine landscapes can change in a number of different ways. For example, when sea levels are low, rivers may coalesce before reaching the sea, whereas when sea levels are higher, rivers may flow independently into the sea. Similarly, tectonic activity may make it possible for one river to "capture" another. The result is that populations that were historically isolated may become connected, and some connected populations may become isolated. We will examine how molecular approaches can be used to examine these processes.

\section{Zoogeographic models of gene flow}

"Zoogeographic models" follows the terminology of Meffe and Vrijenhoek (1988), who were among the first researchers to interpret spatial genetic patterns in streams in terms of a combination of the physical landscape structure (hydrologic or geographic setting) and the biological traits of the organism in question. Given that Meffe and Vrijenhoek's focus was on fishes, which have dispersal-related traits confining them to the water column throughout the life cycle, the zoogeographic models they proposed (known as the "Death Valley" and "stream hierarchy" models; see below) are relevant to organisms with similar dispersal-restrictive traits. Here, we widen the models' perspective beyond fish to include a broader taxonomic and geographic spectrum of stream-dwelling organisms. We also include two additional models that account for the greater diversity of dispersal-related traits encountered in stream organisms other than fishes.

Death Valley model. The two models that Meffe and Vrijenhoek (1988) proposed took into account the shifting balance of dispersal and genetic drift, which depends on local population size (see box 1, table 1). The Death Valley model (DVM) was originally conceived for the unique geographic case in which remnant populations of a species with no capacity for terrestrial movement are found in small, isolated spring pools with no current hydrological connection. Strong isolation in combination with small local population size is expected to cause local genetic drift to dominate populationgenetic structure in the absence of the homogenizing force of dispersal. The predicted result is a large proportion of genetic variation explained at the among-population level, along with a complete lack of spatial genetic structure explained by landscape structure, such as catchment boundaries or even overall geographic distance among populations (figure 1a).

Dalhousie Springs in Australia's Great Artesian Basin provides an ideal aquatic system to test the expectations of the DVM. Here, small springs provide the only perennial
Box 1. Detecting dispersal using genetic variation.

The simplest method to infer patterns of dispersal among populations is to estimate allele frequencies at a number of gene loci and then infer how much dispersal must take place to account for the variance in allele frequencies among populations. Where dispersal is limited among populations, allele frequencies will tend to diverge as a result of random processes or natural selection (Slatkin 1985) and most genetic variation will be among populations. When dispersal is widespread, allele frequencies will tend to be homogeneous because of the mixing of alleles from different populations, and a significant component of the genetic variation will occur within populations, with relatively little among populations (table 1). Effective population size also affects the overall level of genetic variation, as genetic drift, the change in allele or haplotype frequencies as a result of stochastic processes, occurs much faster in small populations than in large ones. Thus, the partitioning of genetic variation within and among populations will depend upon (a) mutation, which produces genetic variation in the first place; (b) genetic drift, reducing variation within populations and increasing variation among populations; (c) dispersal or gene flow, which increases genetic variation within populations but decreases variation among populations; and (d) selection, which can have a variety of effects (table 1). When molecular markers are used to estimate dispersal, the assumption is made that the markers are "neutral," that is, that selection is not affecting the distribution of gene frequencies.

In practice, quantification of genetic variation may be achieved through a variety of molecular methods (Avise 2004). A common term used in this article and in the literature is the haplotype, which refers to a unique sequence of DNA bases along a single chromosome that is transmitted as an intact unit from one generation to the next. Alternate variants of a mitochondrial gene sequence are designated as different haplotypes because the mitochondrial genome is effectively a single chromosome that is inherited maternally without recombination. Two individuals may carry either the same haplotype or different haplotypes for any gene region, depending on how closely related they are and on how much genetic variation is in the population. Genetic variation among haplotypes is the product of mutation at different base positions of the DNA sequence, and given that a sample of haplotypes arose solely through mutation, an evolutionary tree exists that approximates the history of mutational accumulation. This tree can be represented as a haplotype network (see figures 3, 4, and 5).

Table 1. The effects of population processes on the partitioning of genetic variation within and among populations.

\begin{tabular}{lll}
\hline Demographic process & $\begin{array}{l}\text { Genetic variation } \\
\text { among populations }\end{array}$ & $\begin{array}{l}\text { Genetic variation } \\
\text { within populations }\end{array}$ \\
\hline Genetic drift & Increases & Decreases \\
Dispersal (gene flow) & Decreases & Increases \\
Natural selection & Increases or decreases & Increases or decreases \\
\hline
\end{tabular}




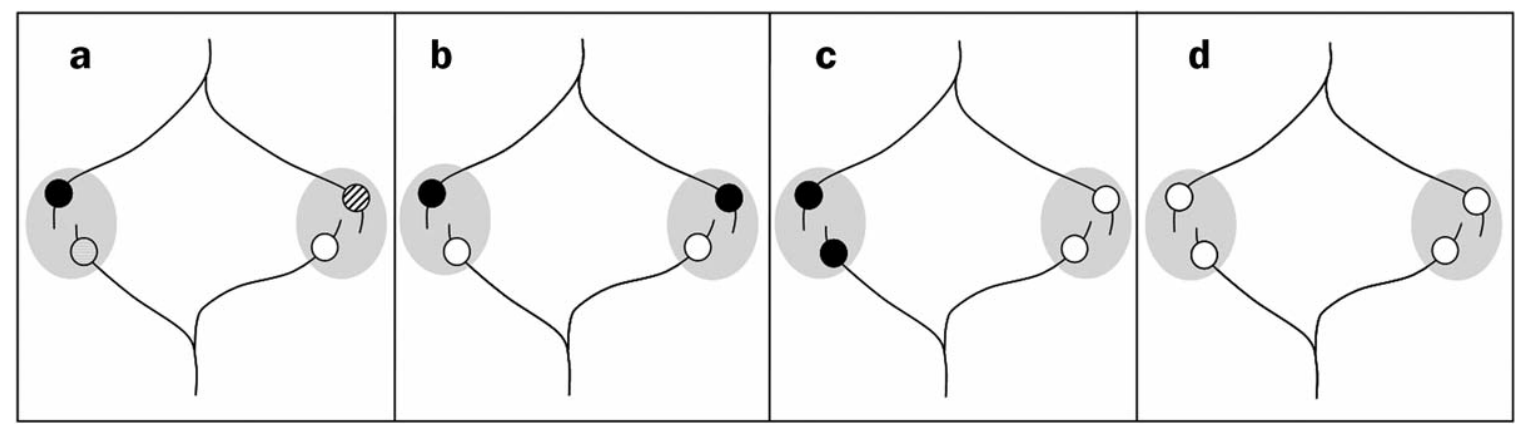

Figure 1. Conceptual representations of genetic patterns arising under each of the four zoogeographic models of gene flow. Each panel shows identical geographic and network structure consisting of two adjacent and unconnected drainage basins (black lines show network structure), the headwaters of which originate in one of two higher-elevation terrestrial localities (gray shading). (a) The Death Valley model predicts strong among-population differences with lack of geographic structure. (b) The stream hierarchy model predicts connectivity among populations within but not among drainage basins. (c) The headwater model predicts connectivity among populations sharing a terrestrial locality of high headwater density, but little connectivity across long distances within networks because of headwater specialization. (d) Widespread gene flow is expected to result in high connectivity and few genetic differences among all localities in a region. Source: Modified from Finn and colleagues (2007).

surface water source. There are about 60 springs in the area that are not hydrologically connected, except during rare bouts of intense rainfall, during which multiple springs may be linked temporarily if they share a common catchment. Colgan and colleagues (2006) found no evidence for contemporary gene flow among individual springs in two species of snails belonging to the genus Caldicochlea (Caldicochlea harrisi and Caldicochlea globosa) in the Dalhousie Springs area. Furthermore, as the DVM predicted, there is no evidence that major catchment boundaries influence genetic structure, nor is there a pattern of overall genetic isolation by distance.

A probable special case of the DVM is exhibited by Metacnephia coloradensis, a rare black fly (Simuliidae) that occurs only in the outlets of large, high-altitude lakes at the upper extent of stream networks in the Rocky Mountains of northern Colorado. Interestingly, although this species occurs within hydrologically connected stream and lake networks, strong local habitat specialization in the headwaters yields an expectation of isolation among local populations. To date, only four $M$. coloradensis populations have been verified, but local population sizes are quite large (Finn and Adler 2006). Unlike most black flies and many other insects, $M$. coloradensis has negligible capacity for among-stream flight dispersal. The adult life span is short, and mating involves crawling rather than flight (Peterson and Kondratieff 1995). Strict habitat specialization further restricts among-population dispersal, which would have to occur across extensive lower-elevation, nonhabitat areas.

As expected, there is strong among-population genetic structure in M. coloradensis; however, some common haplotypes (see box 1) are shared among locations, and there is evidence of isolation by distance, contrary to strict DVM expectations. Large local population sizes are the likely culprit, because the rate of among-population divergence in gene frequencies due to genetic drift (see box 1) will be buffered when the population size is large. In effect, the sharing of haplotypes among these populations is probably a consequence of their recent connection during cooler Pleistocene glacial periods, a signal that has not yet been erased by the forces of mutation and genetic drift (Finn and Adler 2006).

Stream hierarchy model. The second model proposed by Meffe and Vrijenhoek (1988) was the stream hierarchy model (SHM). The SHM predicts that in dendritic stream networks that are at least intermittently connected by surface streamflow, the degrees of connectivity and gene flow vary depending on the spacing of populations within the hierarchical network structure. Relatively unconstrained movement of organisms along branches of the stream network results in local populations being considerably less isolated than expected under the DVM. The degree of isolation is expected to increase, however, as the stream distance separating localities increases; thus, the degree of isolation should follow a hierarchical pattern of genetic structure that reflects the nested arrangement of subcatchments within catchments within major basins of the hierarchical stream network. In other words, the SHM predicts that genetic variance should partition significantly among drainage basins (see figure 1b) at any spatial scale at which basins can be defined within the stream network.

Ultimately, the SHM should hold for organisms with dispersal-related traits that more or less confine them to the water column (such as fish or mussels) or to the stream corridor in general (such as aquatic insects that spend juvenile phases in the stream and have a short terrestrial adult phase in which most flight occurs in the vicinity of the channel). Further, the SHM is most likely applicable for species that 
are not habitat-specialized within a narrow range of the stream network.

The Pacific blue-eye (Pseudomugil signifier), a small Australian fish species, provides a classic example of the SHM. This species is distributed widely in both streams and estuaries in eastern Australia. In a study spanning the full north-south extent of the Pacific blue-eye range, including freshwater samples from 18 coastal drainage basins, McGlashan and Hughes (2002) demonstrated that the majority of total genetic variance $(42 \%)$ could be explained at the among-drainagebasin level. Furthermore, additional variance could be partitioned significantly among hierarchically finer-scaled catchments and subcatchments within individual major drainages, as predicted by the SHM. McGlashan and Hughes's (2002) study design also allowed a test of genetic isolation by hydrological distance among all drainages, which was significant. Essentially, the SHM posits that more distant sites within the hydrological network will be more genetically differentiated, and thus the demonstration of overall isolation by hydrological distance for $P$. signifier complemented the results of the hierarchical drainage basin analysis and supported the SHM for this species.

The SHM also has been upheld for a variety of streamdwelling organisms that are not strictly confined to the aquatic habitat but have dispersal traits that nonetheless limit most movement to within short distances of the stream channel. Aquatic insects, for example, are expected to have limited flight dispersal when either (a) life-history traits or aspects of the environment physically limit dispersal or (b) a species specializes on a rare habitat type, thereby increasing the risk of leaving the natal habitat.

The net-winged midge (Elporia barnardi), which occupies mountain streams in the southwestern Cape region of South Africa, displays both physical constraints on flight movement (short-lived adulthood and mountainous topography) and larval habitat specialization on relatively rare stream sections containing torrential streamflow. Wishart and Hughes (2003) revealed strong SHM adherence for this species. Among 10 sampled locations in a single mountain range, the vast majority of genetic variance was explained by grouping populations among three major drainage basins.

Headwater model. Headwaters are the smallest and uppermost branches of stream networks. Many species specialize on the unique habitat conditions typical of headwater stream reaches (e.g., Lowe and Likens 2005). The headwater model of spatial genetic structure was developed for headwater specialist species with a limited capacity for terrestrial among-stream dispersal. It predicts significant genetic structure at the level of mountaintops or other localized geographic areas containing a relatively high density of headwater streams (figure 1c; Finn et al. 2007). The headwater specialization required by the headwater model, in contrast to the SHM, precludes dispersal throughout the stream network, in effect isolating populations in the uppermost reaches. However, the ability for some terrestrial movement may allow dispersal and gene flow among nearby headwaters, even if this entails crossing catchment boundaries. Hence, the headwater model is supported in a variety of invertebrate species that have some capacity for flight (Finn et al. 2006) or crawling (Ponniah and Hughes 2006, Finn et al. 2007).

The giant water bug Abedus herberti occupies mountain headwater streams in the North American desert Southwest. Abedus herberti is flightless and all life stages require aquatic habitat. Populations are therefore effectively restricted to high-elevation headwaters, which are the only locations in this arid environment that maintain perennial aquatic habitat (Finn et al. 2007). Although flightless, A. herberti can crawl from the stream channel into the adjacent terrestrial landscape, and does so temporarily during rainstorms to avoid flash floods (Lytle 1999). It appears that this infrequent terrestrial movement has allowed some gene flow among neighboring headwaters within small mountain ranges. Although there is also a strong signature of overall among-stream genetic structure, grouping populations according to the mountain range explains a significant proportion of the total genetic variance. Groups composed of populations sharing the same major drainage basin, by contrast, explain none of the variance. The authors suggested that because most major drainage basins include headwaters of more than one mountain range, the lack of significance at the basin and network level could be explained by lower portions of the stream network acting as effective dispersal barriers to these headwater specialists.

Ponniah and Hughes $(2004,2006)$ have shown a similar pattern for several species of the cold-adapted crayfish genus Euastacus, which occupies headwater streams in the Australian Great Dividing Range. In this group, each of 15 species is endemic to a single mountain range; moreover, within mountain ranges, low valleys with warmer stream temperatures are effective barriers to gene flow among mountaintop populations. As with the North American giant water bug, individual species of Australian Euastacus sampled by Ponniah and Hughes (2006) from streams among multiple mountaintops within a range typically showed that mountaintop groups, but not drainage basin groups, explained a significant proportion of overall genetic variance. The authors inferred either contemporary or recent historical movement among nearby streams across drainage divides. These crayfish, like giant water bugs, are able to crawl on land, particularly during wet periods.

Widespread gene flow with isolation by distance. For aquatic species with widespread terrestrial dispersal ability, the effect of landscape hydrological pattern on population genetic structure is typically negligible (figure 1d). Often, genetic isolation by distance is the only spatial pattern that can be expected, with distance measured not as within-network stream distance (as in the SHM) but rather as a straight-line map distance that disregards drainage and network structure. This pattern can be expected in strong-flying insect species that exhibit a stream-dwelling juvenile phase but emerge as flying adults; their dispersal is not particularly restricted by 
biological traits or landscape features. Indeed, many stream restoration projects expect this pattern: "If you build it, they will come" (Hughes 2007, p. 616). As we have described in preceding subsections, however, this prediction probably will not be upheld in species with lower dispersal capacity or habitat specialization. As we will see, even for species without such restrictions, long distances between habitats also can limit gene flow.

There are several examples of widespread gene flow and broadscale isolation by distance in aquatic insects with a strong-flying adult stage. Wilcock and colleagues (2003) showed that the European caddisfly Plectrocnemia conspersa showed little among-stream or among-basin genetic structure within a range of 20 kilometers $(\mathrm{km})$, although genetic distance increased significantly at longer geographical distances. The authors explained this phenomenon as probably resulting from an irregular, clumped spacing of $P$. conspersa's preferred habitat of very small tributaries and seeps: some geological features, urban areas, and the sea separating Great Britain from mainland Europe all represent extensive areas of nonhabitat separating regions of regularly spaced habitat. Geographical distance alone appears to be the key factor that decreases gene flow in this otherwise widely dispersing caddisfly. Wilcock and colleagues revealed significant isolation by distance at broad spatial scales both within Great Britain and across widespread European sample sites.

At the finer spatial scale of a single mountain range, Schultheis and Hughes (2005) showed a similar pattern of lack of genetic structure at the scale of about $20 \mathrm{~km}$ for an Australian caddisfly (Tasimia palpata) in streams of Queensland's Conondale Range. This study revealed an additional interesting pattern: significant genetic structure was observed only at the finest spatial scale, among collection sites in individual streams. This lack of broadscale (among-stream) structure combined with significant fine-scale (within-stream) structure has been documented in several insects to date, and has been hypothesized as deriving from a pattern of "patchy recruitment" (Bunn and Hughes 1997) of new larval generations resulting from only a few mating or oviposition events within stream segments. Thus, although these insects have a strong capacity to disperse among streams-resulting in a lack of genetic structure at this scale-nonrandom oviposition patterns at the local scale followed by limited withinstream larval movement presumably results in significant structure among locations within individual streams.

\section{The dendritic network approach: A unifying framework?} Twenty years after Meffe and Vrijenhoek's (1988) introduction of the SHM framework, there has been a resurgence in stream ecology theory of the importance of network structure on various ecological processes (e.g., Lowe et al. 2006b). Indeed, the SHM seems to foreshadow the formal recognition of the "dendritic ecological network" (Grant et al. 2007), in which all major ecological processes occur throughout the fractal-like branching network, which has elements of selfsimilarity across hierarchical scales. Of particular relevance to dispersal and gene flow is that the shape of the branching network is predicted to have a strong effect on metapopulation processes such as local extinction and colonization by way of the influence of network structure on within-network movement of aquatic organisms (Fagan 2002).

Although these ideas apply most directly to stream organisms with traits that would predispose them to genetic structure predicted by the SHM, the interaction of dendritic network structure with dispersal-related traits and habitat specialization of the species of interest is likely to be the ultimate determinant of resulting landscape-scale genetic structure. Habitat specialization in the smallest and uppermost branches of the network (the headwaters), for example, is expected to prevent long-distance movement within the network and therefore result in genetic patterns predicted by either the headwater model (for organisms with some terrestrial dispersal traits) or the DVM (for organisms with no capacity for terrestrial dispersal; see Finn et al. 2007).

Similarly, as a more general pattern, populations occupying headwaters rather than larger, downstream reaches may have predictable differences in the degree of broadscale genetic structure. In a recent review of studies on a wide range of stream taxa, Hughes (2007) revealed a trend showing greater genetic structure among populations of "upland" (more than 400 meters above sea level) as opposed to lowland species. Although few studies thus far have been designed to directly test the effect of network position on genetic structure, the trend probably results from decreasing levels of connectivity among upland versus lowland sites in stream networks (figure 2). In particular, confluences of smaller streams with larger ones can impede movement (see Fagan 2002).

Most studies thus far have focused at the relatively fine scale of single major drainage basins, but even at this scale, evidence of the effect of network location on population genetic structure has been apparent. These effects extend across multiple animal phyla. Berg and colleagues (2007), for example, revealed that mussels in smaller streams within a drainage basin in the central United States showed decreased among-population gene flow as compared with large-stream species. Here, dispersal depends primarily on the movement patterns of fish that provide transport for the mussels' larvae (glochidia). Fish species used by the smaller-stream mussel species are smaller, move shorter distances, and thus are presumably more isolated among streams than the larger fish counterparts to which the glochidia of larger-stream mussel species attach.

Cook and colleagues (2007) showed a similar pattern for two species of sympatric Paratya shrimp occurring in both upland and lowland streams in the Granite Creeks area of southeastern Australia. The authors speculated that steeper gradients in the smaller upland streams negatively affect shrimp movement within the network, therefore causing decreased gene flow among locations even within individual streams in the uplands. For stream-dwelling salamanders in the Hubbard Brook Experimental Forest in New Hampshire, Lowe and colleagues (2006a) revealed a pattern that they termed "isolation by slope," in which the genetic distance 


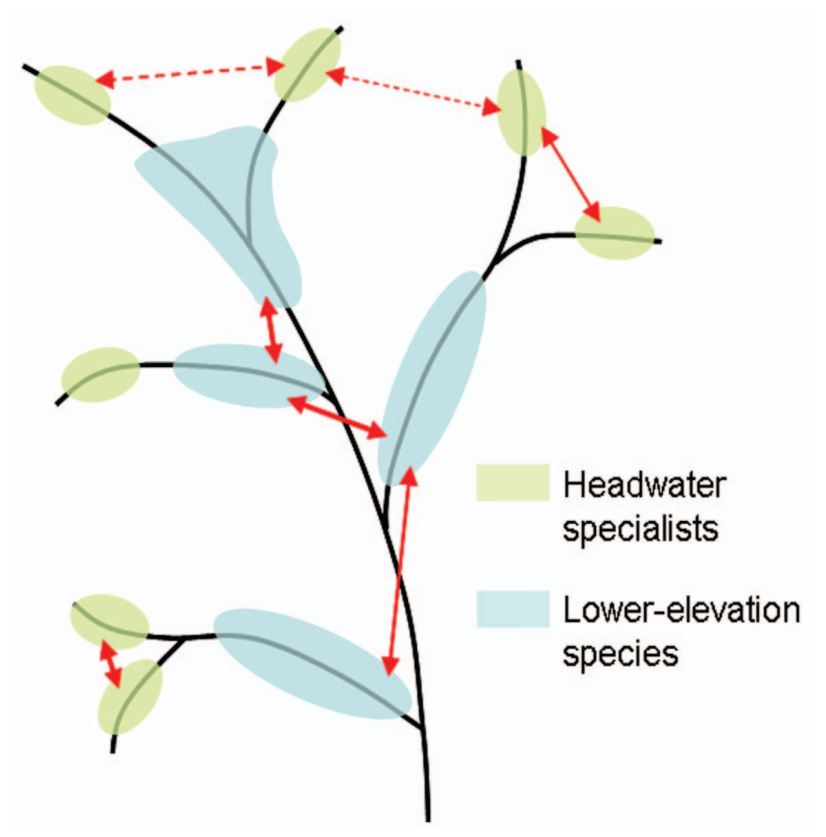

Figure 2. Hypothetical stream network arrangement showing population distribution of headwater (in green) and lower-elevation (in blue) stream-dwelling species. Smaller local population sizes and stronger isolation in distant tips of the network allow a general prediction that headwater specialist species will show stronger amongpopulation genetic structure. Species occupying lower segments of streams, by contrast, are expected to have larger population sizes and greater connectivity as a result of shorter among-population distances. Solid arrows represent potential within-network gene flow; broken arrows indicate out-of-network gene flow for species with a limited ability for such movement. Naturally, species strictly confined to the aquatic habitat will have no such movement.

between pairs of populations separated by similar stream distances was significantly greater with increasing altitudinal difference between sites. These patterns suggest that the steeper gradients more typical of headwater sections of stream networks may be playing a significant role in limiting dispersal and differentiating populations.

There is also some evidence that local genetic diversity is lower in upland populations than in lowland ones. Martin and Wilcox (2004) demonstrated this pattern for isolated desert pupfish populations in the US Southwest. This pattern is expected, given the greater isolation of populations occurring in upper branches of stream networks, particularly if local effective population sizes are smaller in the smaller upland locations. At the same time, however, the increased genetic structure expected higher in the stream network is equivalent to the greater among-population diversity (analogous to beta diversity in community ecology) expected in headwaters versus tailwaters.

\section{Inferring historical processes responsible for current distributions of aquatic species}

Many species of obligate freshwater organisms, including some of those expected to follow the SHM, have distributions that range across more than one drainage system. Terrestrial biogeographical literature proposes that such fragmented distributions must have arisen either through vicariance, such that the distribution was once continuous but has been isolated as a result of a division of the habitat, or dispersal, whereby individuals of the species have managed to disperse from one patch of habitat to another (Lomolino et al. 2006). Phylogeographic approaches have been used to distinguish between these scenarios (Avise et al. 1987) — that is, to find out whether the populations have been severed and separated for a long evolutionary history, or whether there is evidence of current or recent dispersal between them (figure 3).

Populations of a species in two adjacent drainages that represent two distinct groups, separated by significant genetic divergence (figure 3a), are likely to have been separated for a long period of evolutionary time. In contrast, if the populations represent groups separated by only limited divergence, the separation is much more recent (figure $3 \mathrm{~b}$ ). If haplotypes (see box 1) from both drainages are spread throughout the network and are shared between drainages, continued or very recent dispersal has occurred across the drainage boundary (figure 3c). When significant divergence occurs within a species, but the two groups occur together across both drainages, a period of isolation (when divergence would have occurred) followed by secondary contact is inferred (figure 3d).

Paratya australiensis is a freshwater shrimp that inhabits coastal and inland waterways throughout eastern Australia (Williams 1977). Early studies suggested that the wide species distribution was probably a result of an estuarine larval stage resulting in dispersal of larvae between nearby and more distant estuaries through ocean currents, but molecular studies have shown that the species is made up of a number of highly divergent groups, some of which are widespread whereas others are endemic to particular river systems (Baker et al. 2004, Cook et al. 2006). Analysis of mitochondrial DNA shows high levels of divergence between populations in two adjacent subcatchments of the Brisbane River in southeastern Queensland, Australia, suggesting that these populations have been isolated for long periods of time, probably since the Pliocene (e.g., historical fragmentation, figure 3a; Hurwood et al. 2003). Clearly, widespread dispersal through marine pathways is not the explanation for the distribution. More likely, the nominal "species" consists of a number of "cryptic species" (Bickford et al. 2007). Indeed, Cook and colleagues (2007) have used allozymes to show that at least two of the lineages that occur together within the same stream in southern Australia do not interbreed, suggesting that lineages may constitute genuine reproductively isolated species.

Cheumatopsyche species AV1 is a caddisfly that occurs throughout the rivers in the area around Sydney in eastern Australia. A study using mitochondrial DNA sequence data 
identified a large number of haplotypes, most of which were shared between multiple catchments (Baker et al. 2003). This result led researchers to infer that dispersal between adjacent catchments is frequent, and that flight by the adult caddis is the major dispersal mechanism responsible for this pattern (i.e., fitted expectations of the widespread gene flow model; see figure $3 c)$.

A different pattern was observed in Hyrtl's tandan (Neosilurus hyrtlii), a freshwater catfish that is widespread in inland waterways in eastern and northern Australia. The species occurs in both the Lake Eyre basin and the Murray-Darling basin. Analysis of mitochondrial DNA shows that individuals in the Murray-Darling and the Lake Eyre basins represent two distinct groups that are separated from one another by only a single mutational step (Huey et al. 2006). This implies that although there is no current gene flow between populations in the two drainages, connections between them have been severed relatively recently (figures $3 \mathrm{~b}, 4 \mathrm{~d}$ ).

Cherax destructor is a small freshwater crayfish with a widespread distribution across a number of inland Australian rivers. In particular, it occurs in both the Warrego River and Cooper Creek (figure 4e). While the Warrego is part of the Murray-Darling system, which flows into the sea in southern Australia, Cooper Creek flows into a large inland lake, Lake Eyre. Phylogeographic analysis of mitochondrial DNA haplotypes was used to infer the history of crayfish dispersal within and between these drainage systems. Hughes and Hillyer (2003) showed that the species was most likely isolated between the two drainages some time in the past, but then a subsequent secondary colonization occurred from the Murray-Darling to the Lake Eyre basin (figures 3d, 5e).

\section{Inferring changes to the freshwater landscape using molecular data}

Acceptance of the theory of continental drift in the late 1960s revolutionized our understanding of the distribution patterns of organisms on a global scale (Lomolino et al. 2006). Likewise, geological information has played a key role in furthering our understanding of dispersal and population structure at smaller scales in the field of molecular freshwater ecology. Hydrological barriers may be imposed on riverine systems by mechanisms such as historical sea-level

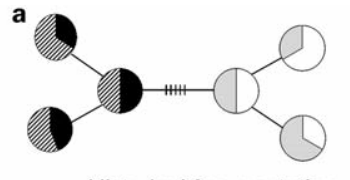

Historical fragmentation

b

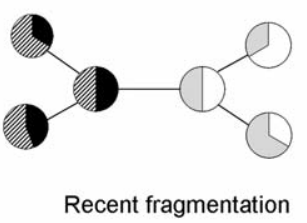

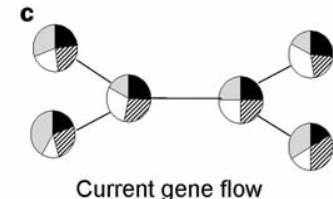

Current gene flow

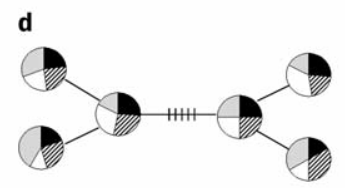

Secondary contact

Figure 3. Hypothetical haplotype networks expected for each of four historical processes that may shape the distribution of aquatic fauna across adjacent drainages. The left side of the figure shows two adjacent drainages, separated across a drainage divide. The four networks represent possible outcomes of phylogeographic analysis. Each circle represents a unique haplotype or DNA sequence (see box 1); the lines show how each is related to the others. Circles separated by a single line differ by a single ion. Crossbars indicate additional mutations. (a) The result expected where (b) The result expected when drainages are currently isolated, but where isolation has been recent. The haplotypes in each drainage form distinct groupings, but they have experienced secondary contact. There are two groups of haplotypes separated by a number of mutational steps, but they are not restricted to particular drainages. Note: $(a)$ and (b) are alternative versions of the stream hierarchy model, and (c) and (d) are alternatives under widespread gene flow.

changes, tectonic activity, erosion, and glaciation (Craw et al. 2007). Geological reconstructions and the timing of these events provide testable hypotheses for phylogeographic patterns of freshwater organisms; interestingly, some phylogeographic results may improve our understanding of the geological structure of historical riverine connections. The heuristic association between the physical history of drainages and the phylogeography of their freshwater inhabitants is analogous to studies of host-parasite cospeciation, in which rivers are hosts and freshwater organisms represent parasites (Waters et al. 2007).

Eustatic sea-level fluctuations are predicted to have a major impact on the connectivity of freshwater-limited fauna that cannot migrate via the sea. The refilling of ocean basins by glacier meltwater at the end of ice ages is an example of eustatic sea-level rise. Rivers may be isolated or connected, depending on whether their tributary junctions are inundated or exposed by the changing sea levels (figure 5a). The phylogeographic signature of the fluctuating sea level was revealed in studies on a freshwater shrimp (Macrobrachium rosenbergii) found throughout the Indo-Australian archipelago (de Bruyn et al. 2004, de Bruyn and Mather 2007). De Bruyn and colleagues (2004) showed that shrimps from streams draining into ocean waters of the Gulf of Carpentaria in 


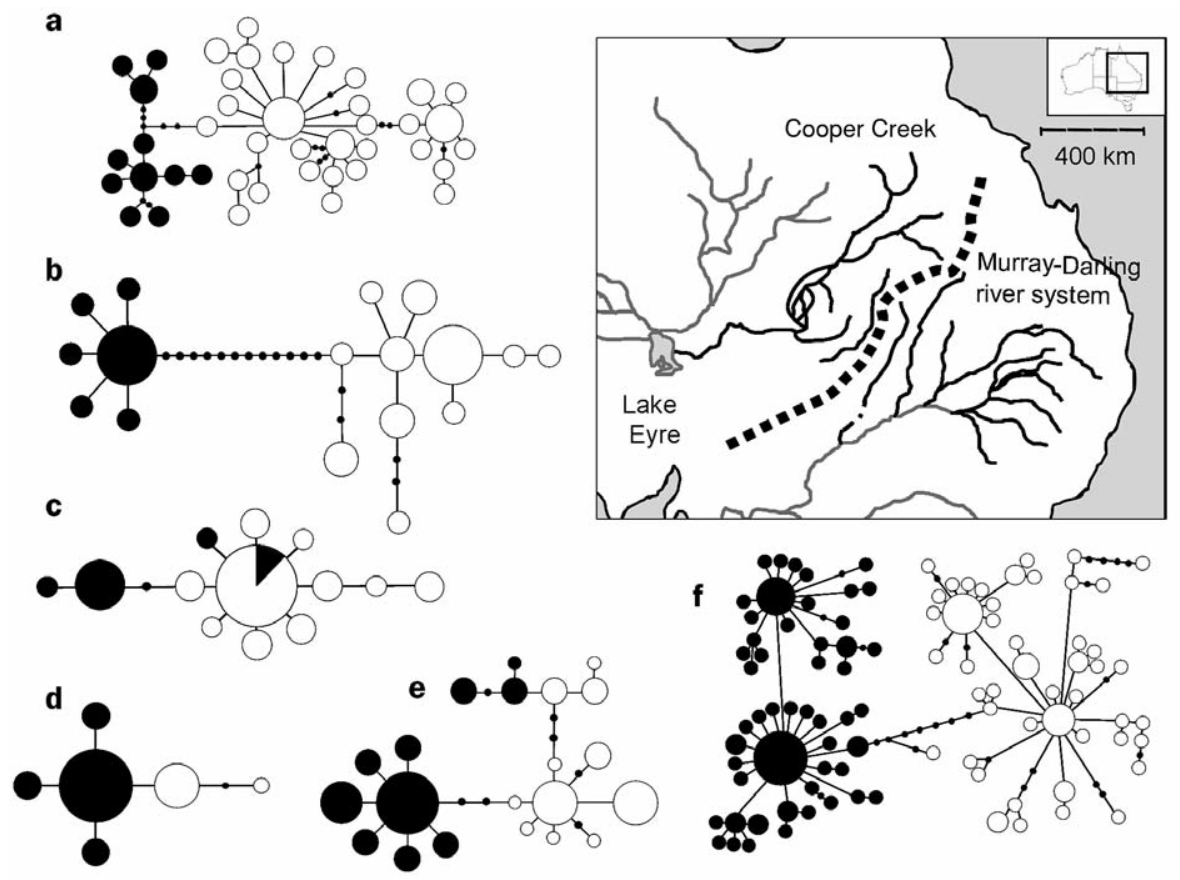

Figure 4. Mitochondrial DNA haplotype networks depicting genealogical relationships between freshwater organisms sampled in Cooper Creek (Lake Eyre basin, LEB) and Murray-Darling basin (MDB) river systems. Haplotypes sampled from the LEB are shown as black circles, those from the MDB as white circles. Haplotypes shared by both basins are shown in pie form, indicating the frequency with which haplotypes were sampled from respective basins. Haplotype size reflects relative frequency in each sample (sample sizes and collection locality information can be obtained from original publications listed below). The inset map depicts the two drainage basins with sampled rivers shown in black and dashed line emphasizing the drainage boundary. (a) Freshwater mussel (Velesunio spp. C), data from Hughes and colleagues (2004). (b) Australian smelt (Retropinna semoni), data from Hughes and Hillyer (2006). (c) Bony bream (Nematolosa erebi), data from Hughes and Hillyer (2006). (d) Catfish (Neosilurus hyrtlii), data from Huey and colleagues (2006). (e) Freshwater crayfish (Cherax destructor), data from Hughes and Hillyer (2003). (f) Freshwater prawn (Macrobrachium australiense), data from Carini and Hughes (2004).

northern Australia were closely related to each other compared with other populations - they were connected through a vast fresh to brackish lake that existed in the center of the Gulf as recently as 10,000 years ago before inundation by rising quaternary sea levels (figure 5b; de Bruyn et al. 2004). Indeed, the timing of phylogeographic breaks across the whole Indo-Australian range of this species corresponds well to major sea-level fluctuations occurring since the late Miocene (approximately 5 million years ago), indicating that ocean levels have governed the historical movement and distribution of this freshwater species (de Bruyn and Mather 2007).

The legacy of Pleistocene sea-level fluctuations is also evident in the phylogeographic structuring of a freshwater shrimp (Caridina indistincta) and a fish (Rhadinocentrus ornatus) found on sand islands and adjacent mainland habitats of eastern Australia (Page and Hughes 2007). These taxa show complementary shallow phylogeographic patterns, suggesting that colonization of lakes on the sand islands may have been achieved during periods of lowered sea level when rivers flowed past the lakes toward the continental shelf. A striking deviation to this pattern was discovered in the case of one highly divergent shrimp lineage ( $C$. indistincta sp. C1) that is restricted to just two islands. Molecular dating of the split between this lineage and its nearest relative along with geological dating of the dune lake habitats suggest the shrimps are orders of magnitude older than the lakes they currently occupy, leaving the history of colonization a mystery (Page and Hughes 2007).

In New Zealand, many geological changes to the landscape are reasonably well understood, and radiocarbon dating and oxygen isotope analyses suggest the approximate time that they occurred (e.g., Craw et al. 2007). The southwestern movement of the Pacific Plate relative to the Australian Plate has caused an uplift of mountain ranges over the last 5 million years, and the geometry of river drainages has changed remarkably over this time (Craw et al. 2007, Waters et al. 2007). Such changes have allowed a group of New Zealand molecular ecologists to test whether the hypothesized drainage rearrangements are supported by genetic data from the rivers' "parasitic" inhabitantsfreshwater fish. They have not only tested the hypotheses that these changes have occurred but also used the timing of the geological events to obtain more accurate calibrations for the rate of molecular divergence.

River capture refers to the displacement of stream sections between adjacent catchments (figure $5 c$ ). In New Zealand's South Island, geologists have pinpointed a recent river capture event involving the displacement of a section of the southward flowing Oreti River into the northward flowing Von River, an event estimated to have occurred 11,000 to 13,000 years ago (Craw et al. 2007). Burridge and colleagues (2007) predicted that if river capture is responsible for the distribution of freshwater-limited galaxiid fish, then the genetic relationship among populations of the Oreti and Von rivers should reflect historical rather than contemporary catchment boundaries within the framework of the stream hierarchy model. Using data from mitochondrial and nuclear DNA, these authors revealed a phylogeographic pattern consistent with the capture event. Populations in the Von River had closer affinities to those in the Oreti than they did to other populations in their own northern drainage system 
(Burridge et al. 2007). The coexistence of the original genetic lineage, as well as the "captured" lineage in the northern drainage, was probably facilitated by gorges that impeded the upstream movement of the original lineage, preventing mixing of the two lineages and preserving the genetic corroboration of river capture.

Waters and colleagues (2007) take the above observations one step further by using the geological date of another river capture event $(70,000$ to 130,000 years ago $)$ to calibrate the rate of mitochondrial DNA base substitution (i.e., the "molecular clock"). Using a variety of calibration methods, high rates of substitution were recovered (10\% to $20 \%$ per million years), suggesting that the molecular clock in galaxiid fish is ticking at a much faster rate than conventional estimates suggest (approximately $1 \%$ to $2 \%$ per million years). Waters and colleagues (2007) argued that these results agree with the theory recently championed by Ho and Larson (2006): molecular rate estimates are time dependent, so more recent calibration times return higher rate estimates, a relationship that declines monotonically as longer calibration times are used. This theory is controversial because of its wide-ranging implications for evolutionary biology (e.g., Bandelt 2008), and it is likely that river capture events will provide a tractable experimental framework for further exploration of the issue.

Australia has experienced little geological activity during the tertiary and quaternary, when all of its major drainage basins were established (Unmack 2001). Despite this, two major drainages in eastern Australia (the MurrayDarling basin and the Lake Eyre basin) share a number of freshwater species in common, including fish, mollusks, and crustaceans. This suggests that these two drainages have been connected at some time in the recent past, although the timing, location, and mechanism of this connection are poorly understood (Unmack 2001). Evidence from mitochondrial DNA data for a freshwater mussel (Hughes et al. 2004), two crustaceans (Hughes and Hillyer 2003, Carini and Hughes 2004), and three fish species (Huey et al. 2006, Hughes and Hillyer 2006) all suggest that the populations have been connected during the Pleistocene (within the last two million years).

We reanalyzed data from each of these studies to obtain a biological estimate of the time that the two basins split. The method used (MDIV, Nielsen and Wakeley 2001; see http://fisher.berkeley.edu/cteg/ software.html) estimates the time of population divergence assuming a DNA substitution rate for each species and accounts for both postdivergence migration and the effects of ancestral population size in the calculation. Haplotype net-
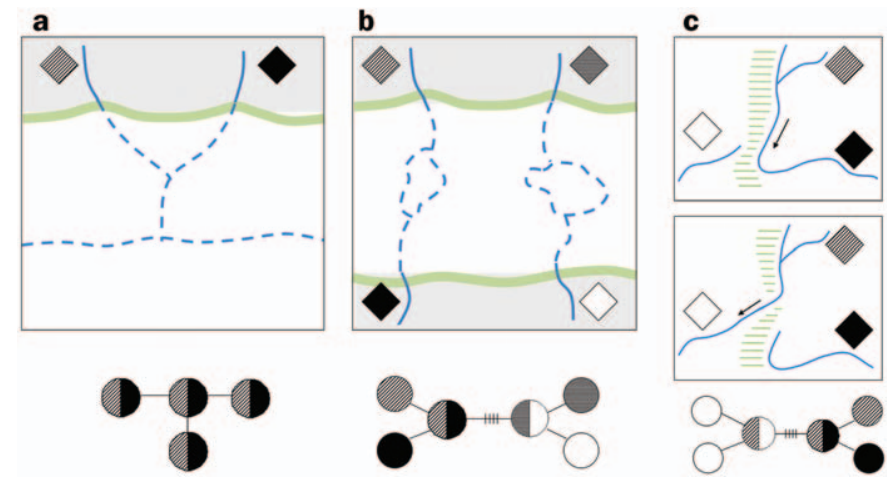

Figure 5. Historical changes to river structure and the associated pattern of genetic variation expected in contemporary populations. Sampled populations are indicated by diamonds in each diagram; a hypothetical haplotype network below each panel shows how genetic variation is distributed across the populations in each case. (a) Isolation of stream branches as a result of sealevel rise. Dashed blue line denotes the historical shoreline and tributary junction, while the green line denotes the current shoreline. Although contemporary connection between freshwater populations is absent, both share the same haplotypes, owing to their recent former connection. (b) Genetic affinity between freshwater populations on different landmasses due to historical connection through lakes during periods of lowered sea level. (c) River capture resulting in secondary contact of formerly isolated freshwater populations. The upper panel shows the historical scenario, depicting the flow of eastern and western rivers isolated by a geological barrier (green lines); the lower panel shows the contemporary scenario resulting from geological rearrangement of the barrier and capture of the upstream section of the eastern river by the western river. One of several possible genetic signatures of secondary contact resulting from the river capture is shown in the haplotype network.

works for each of the six species in figure 4 indicate that genetic diversity and the degree of interbasin divergence vary considerably among species. Estimates of timing of the population split between the two basins are also variable; they range from approximately 70,000 years for the catfish to approximately 1.7 million years for the mussel (table 2 ).
Table 2. Maximum likelihood estimates of the time of population splitting ( $\mathrm{t}$ ) for six obligate freshwater organisms sampled in the Lake Eyre and Murray-Darling drainage basins, Australia.

\begin{tabular}{llcl}
\hline Species & Common name & $\begin{array}{c}\boldsymbol{t} \text { (years since } \\
\text { population split) }\end{array}$ & Data source \\
\hline Velesunio sp. C & Freshwater mussel & $1,786,469$ & Hughes et al. 2004 \\
Retropinna semoni & Australian smelt & $1,577,899$ & Hughes and Hillyer 2006 \\
Nematolosa erebi & Bony bream & 118,727 & Hughes and Hillyer 2006 \\
Neosilurus hyrtlii & Catfish & 73,789 & Huey et al. 2006 \\
Cherax destructor & Freshwater crayfish & 281,020 & Hughes and Hillyer 2003 \\
Macrobrachium australiense & Freshwater prawn & 995,406 & Carini and Hughes 2004 \\
& & & \\
\multicolumn{2}{c}{ Note: Data source gives the reference for mitochondrial sequence data and appropriate DNA substitution rate } \\
for each taxon.
\end{tabular}


The apparent differences between species in timing of separation could be due to vagaries of the molecular clock or to the fact that the drainages have been connected multiple times during the Pleistocene, and only some species have managed to disperse across the boundaries. Both of these factors probably play a part, as the three species exhibiting more recent divergences (catfish, bony bream, and crayfish) are also more connected within their respective drainages, suggesting that they are more efficient dispersers in these inland systems (Hughes and Hillyer 2003, 2006, Huey et al. 2006). Of particular significance is that, if we accept that the molecular clock ticks faster when populations first diverge (i.e., within the first million years; Ho and Larson 2006), then these desert populations may have been connected even more recently than our estimates suggest. Recent geological studies have revealed evidence for several large discharge events from the Murray-Darling and Lake Eyre systems since the onset of severe aridity in the mid-Pleistocene (Gingele et al. 2007, Maroulis et al. 2007). This leaves open the possibility that occasional large flood events were responsible for episodic connection of the Lake Eyre and Murray-Darling basins and for production of the observed phylogeographic patterns. In this case, then, genetic evidence sheds some light on the historical connectivity of Australia's inland drainage basins, where geomorphological evidence is currently lacking. Elucidation of the locations and mechanisms involved in these putative drainage connections awaits further study.

Clearly, the most effective pathway toward a better understanding of the history of freshwater ecosystems will be achieved through complementary studies of geomorphology and genetics, although coordinated research programs of this nature are only just beginning to emerge and produce valuable insights (e.g., Craw et al. 2007).

\section{Conclusions}

We now have the potential to use population genetic data to inform watershed management decisions. First, we have models of population structure that accommodate the dendritic habitat and life-history peculiarities of freshwater taxa, so knowledge of the habitat requirements and life histories of species can be used to predict the structure of populations. Thus, we can predict results for the species, the pattern, and the scale of recolonization following local extinctions, and we can predict the effects that degrading or disturbing particular sections of stream habitat will have on connectivity. In particular, it is clear that although many managers assume that catchments are the appropriate units of management, this is not necessarily the case for many aquatic species, especially those with specialized habitat requirements. Second, we have the molecular tools and analytical methods available to determine the evolutionary history of species. This information will assist in decisions regarding the importance of particular river sections or whole streams for the conservation of biodiversity. Third, we are just beginning to use genetic data to corroborate, or in some cases question, hypotheses about geomorphological history of drainages. This is an exciting new area, one that will require scientists to work in multidisciplinary teams to unravel the history of our landscapes.

\section{Acknowledgments}

For support, advice and discussion, we thank Dave Lytle, LeRoy Poff, and members of the Australian Rivers Institute Molecular Ecology Laboratory at Griffith University. Mark Ponniah conducted the MDIV analyses, and figures were produced with the assistance of Giovannella Carini, Alison Mclean, and Mia Hillyer.

\section{References cited}

Avise JC. 2004. Molecular Markers, Natural History, and Evolution. Sinauer. Avise JC, Arnold J, Ball RM, Bermingham E, Lamb T, Neigel JE, Reeb CA, Saunders NC. 1987. Intraspecific phylogeography: The mitochondrial DNA bridge between population genetics and systematics. Annual Review of Ecology and Systematics 18: 489-522.

Baker AM, Williams SA, Hughes JM. 2003. Patterns of spatial genetic structuring in a hydropsychid caddisfly (Cheumatopsyche sp AV1) from southeastern Australia. Molecular Ecology 12: 3313-3324.

Baker AM, Hurwood DA, Krogh M, Hughes JM. 2004. Mitochondrial DNA signatures of restricted gene flow within divergent lineages of an atyid shrimp (Paratya australiensis). Heredity 93: 196-207.

Bandelt H-J. 2008. Clock debate: When times are a-changin': Time dependency of molecular rate estimates: Tempest in a teacup. Heredity 100: 1-2.

Berg DJ, Christian AD, Guttman SI. 2007. Population genetic structure of three freshwater mussel (Unionidae) species within a small stream system: Significant variation at local spatial scales. Freshwater Biology 52: 1427-1439.

Bickford D, Lohman DJ, Sodhi NS, Ng PKL, Meier R, Winker K, Ingram KK, Das I. 2007. Cryptic species as a window on diversity and conservation. Trends in Ecology and Evolution 22: 148-155.

Bohonak AJ. 1999. Dispersal, gene flow, and population structure. Quarterly Review of Biology 74: 21-45.

Bunn SE, Hughes JM. 1997. Dispersal and recruitment in streams: Evidence from genetic studies. Journal of the North American Benthological Society 16: 338-346.

Burridge CP, Craw D, Waters JM. 2007. An empirical test of freshwater vicariance via river capture. Molecular Ecology 16: 1883-1895.

Carini G, Hughes JM. 2004. Population structure of Macrobrachium australiense (Decapoda: Palaemonidae) in Western Queensland, Australia: The role of contemporary and historical processes. Heredity 93: 350-363.

Colgan DJ, Ponder WF, Da Costa P. 2006. Mitochondrial DNA variation in an endemic aquatic snail genus, Caldicochlea (Hydrobiidae; Caenogastropoda) in Dalhousie Springs, an Australian arid-zone spring complex. Molluscan Research 26: 8-18.

Cook BD, Baker AM, Page TJ, Grant SC, Fawcett JH, Hurwood DA, Hughes JM. 2006. Biogeographic history of an Australian freshwater shrimp, Paratya australiensis (Atyidae): The role life history transition in phylogeographic diversification. Molecular Ecology 15: 1083-1093.

Cook BD, Bunn SE, Hughes JM. 2007. A comparative analysis of population structuring and genetic diversity in sympatric lineages of freshwater shrimp (Atyidae: Paratya): Concerted or independent responses to hydrographic factors? Freshwater Biology 52: 2156-2171.

Craw D, Burridge C, Anderson L, Waters JM. 2007. Late Quaternary river drainage and fish evolution, Southland, New Zealand. Geomorphology 84: 98-110.

de Bruyn M, Mather PB. 2007. Molecular signatures of Pleistocene sea-level changes that affected connectivity among freshwater shrimp in IndoAustralian waters. Molecular Ecology 16: 4295-4307.

de Bruyn M, Wilson JC, Mather PB. 2004. Reconciling geography and genealogy: Phylogeography of giant freshwater prawns from the Lake Carpentaria region. Molecular Ecology 13: 3515-3526. 


\section{1st Century Directions in Biology}

Fagan WF. 2002. Connectivity, fragmentation, and extinction risk in dendritic metapopulations. Ecology 83: 3243-3249.

Finn DS, Adler PH. 2006. Population genetic structure of a rare highelevation black fly, Metacnephia coloradensis, occupying Colorado lake outlet streams. Freshwater Biology 51: 2240-2251.

Finn DS, Theobald DM, Black WC, Poff NL. 2006. Spatial population genetic structure and limited dispersal in a Rocky Mountain alpine stream insect. Molecular Ecology 15: 3553-3566.

Finn DS, Blouin MS, Lytle DA. 2007. Population genetic structure reveals terrestrial affinities for a headwater stream insect. Freshwater Biology 52: 1881-1897.

Gingele F, De Deckker P, Norman M. 2007. Late Pleistocene and Holocene climate of SE Australia reconstructed from dust and river loads deposited offshore the river Murray mouth. Earth and Planetary Science Letters 255: 257-272.

Grant EHC, Lowe WH, Fagan WF. 2007. Living in the branches: Population dynamics and ecological processes in dendritic networks. Ecology Letters 10: 165-175.

Ho SYW, Larson G. 2006. Molecular clocks: When times are a-changin'. Trends in Genetics 22: 79-83.

Huey JA, Hughes JM, Baker AM. 2006. Patterns of gene flow in two species of eel-tailed catfish, Neosilurus hyrtlii and Porochilus argenteus (Siluriformes: Plotosidae), in western Queensland's dryland rivers. Biological Journal of the Linnean Society 87: 457-467.

Hughes JM. 2007. Constraints on recovery: Using molecular methods to study connectivity of aquatic biota in rivers and streams. Freshwater Biology 52: 616-631.

Hughes JM, Hillyer MJ. 2003. Patterns of connectivity among populations of Cherax destructor (Decapoda: Parastacidae) in western Queensland, Australia. Marine and Freshwater Research 54: 587-596.

- 2006. Mitochondrial DNA and allozymes reveal high dispersal abilities and historical movement across drainage boundaries in two species of freshwater fishes from inland rivers in Queensland, Australia. Journal of Fish Biology 68: 270-291.

Hughes JM, Baker AM, Bartlett C, Bunn S, Goudkamp K, Somerville J. 2004. Past and present patterns of connectivity among populations of four cryptic species of freshwater mussels Velesunio spp. (Hyriidae) in central Australia. Molecular Ecology 13: 3197-3212.

Hurwood DA, Hughes JM, Bunn SE, Cleary C. 2003. Population structure in the freshwater shrimp (Paratya australiensis) inferred from allozymes and mitochondrial DNA. Heredity 90: 64-70.

Lomolino MV, Riddle BR, Brown JH. 2006. Biogeography. Sinauer.

Lowe WH, Likens GE. 2005. Moving headwater streams to the head of the class. BioScience 55: 196-197.

Lowe WH, Likens GE, Power ME. 2006a. Linking scales in stream ecology. BioScience 56: 591-597.

Lowe WH, Likens GE, McPeek MA, Buso DC. 2006b. Linking direct and indirect data on dispersal: Isolation by slope in a headwater stream salamander. Ecology 87: 334-339.

Lucas MC, Baras E. 2000. Methods for studying spatial behaviour of freshwater fishes in the natural environment. Fish and Fisheries 1: 283-316.

Lytle DA. 1999. Use of rainfall cues by Abedus herberti (Hemiptera: Belostomatidae): A mechanism for avoiding flash floods. Journal of Insect Behavior 12: 1-12.

Mackay RJ. 1992. Colonization by lotic macroinvertebrates: A review of processes and patterns. Canadian Journal of Fisheries and Aquatic Sciences 49: 617-628.

MacNeale KH, Peckarsky BL, Likens GE. 2005. Stable isotopes identify dispersal patterns of stonefly populations living along stream corridors. Freshwater Biology 50: 1117-1130.
Maroulis JC, Nanson GC, Price DM, Pietsch T. 2007. Aeolian-fluvial interaction and climate change: Source-bordering dune development over the past $\sim 100$ ka on Cooper Creek, central Australia. Quaternary Science Reviews 26: 386-404.

Martin AP, Wilcox JL. 2004. Evolutionary history of Ash Meadows pupfish (genus Cyprinodon) populations inferred using microsatellite markers. Conservation Genetics 5: 769-782.

McGlashan DJ, Hughes JM. 2002. Extensive genetic divergence among populations of the Australian freshwater fish, Pseudomugil signifer (Pseudomugilidae), at different hierarchical scales. Marine and Freshwater Research 53: 897-907.

Meffe GK, Vrijenhoek RC. 1988. Conservation genetics in the management of desert fishes. Conservation Biology 2: 157-169.

Nielsen R, Wakeley J. 2001. Distinguishing migration from isolation: A Markov Chain Monte Carlo approach. Genetics 158: 885-896.

Page TJ, Hughes JM. 2007. Phylogeographic structure in an Australian freshwater shrimp largely pre-dates the geological origins of its landscape. Heredity 98: 222-231.

Peterson BV, Kondratieff BC. 1995. The black flies (Diptera: Simuliidae) of Colorado: An annotated list with keys, illustrations and descriptions of three new species. Memoirs of the American Entomological Society 42: $1-121$.

Ponniah M, Hughes JM. 2004. The evolution of Queensland spiny mountain crayfish of the genus Euastacus, I: Testing vicariance and dispersal with interspecific mitochondrial DNA. Evolution 58: 1073-1085.

- 2006. The evolution of Queensland spiny mountain crayfish of the genus Euastacus, II: Investigating simultaneous vicariance with intraspecific genetic data. Marine and Freshwater Research 57: 349-362.

Schultheis AS, Hughes JM. 2005. Spatial patterns of genetic structure among populations of a stone-cased caddis (Trichoptera: Tasimiidae) in southeast Queensland, Australia. Freshwater Biology 50: 2002-2010.

Slatkin M. 1985. Gene flow in natural populations. Annual Review of Ecology and Systematics 16: 393-430.

Stanley EH, Luebke MA, Doyle MW, Marshall DW. 2002. Short-term changes in channel form and macroinvertebrate communities following low-head dam removal. Journal of the North American Benthological Society 21: $172-187$.

Unmack PJ. 2001. Biogeography of Australian freshwater fishes. Journal of Biogeography 28: 1053-1089.

Waters JM, Rowe DL, Apte S, King TM, Wallis GP, Anderson L, Norris RJ, Craw D, Burridge CP. 2007. Geological dates and molecular rates: Rapid divergence of rivers and their biotas. Systematic Biology 56: 271-282.

Wilcock HR, Nichols RA, Hildrew AG. 2003. Genetic population structure and neighbourhood population size estimates of the caddisfly Plectrocnemia conspersa. Freshwater Biology 48: 1813-1824.

Williams WD. 1977. Some aspects of the ecology of Paratya australiensis (Crustacea: Decapoda: Atyidae). Marine and Freshwater Research 28: 403-415.

Wishart MJ, Hughes JM. 2003. Genetic population structure of the netwinged midge, Elporia barnardi (Diptera: Blephariceridae), in streams of the south-western Cape, South Africa: Implications for dispersal. Freshwater Biology 48: 28-38

Jane M. Hughes (e-mail: jane.hughes@griffith.edu.au) and Daniel J. Schmidt are with eWater Cooperative Research Centre, Australian Rivers Institute, Griffith University, in Queensland, Australia. Debra S. Finn is currently with EAWAG, Aquatic Ecology Department, Department of Zoology, Oregon State University, Corvallis. 
Reproduced with permission of the copyright owner. Further reproduction prohibited without permission. 